\section{IJ $\$ E R$}

ISSN: 2149-5939
International Journal of Social Sciences and Education Research

Online, http://dergipark.gov.tr/ijsser

Volume: 1(1), 2015

\title{
Mülteci krizi sürecinde Avrupa'da artan milliyetçilik söyleminin sosyal medyaya yansıması
}

\author{
Reflections of the nationalist expressions to the social media that grows in Europe \\ during the refugee crisis
}

Mustafa Özgür Seçim ${ }^{1}$

\begin{abstract}
Received Date: $01 / 01 / 2015$
Accepted Date: $01 / 02$ / 2015

$\ddot{O} z$

2011 yılında, Suriye'de patlak veren iç savaş, beraberinde Avrupa Birliği bölgesine yeni bir mülteci krizini de sunmuştur. İç savaş sonrası bilanço resmi rakamlara göre 130 binden fazla kişinin hayatını kaybettiği, üç milyona yakın kişinin ise ülke dışına çıkmak durumunda kaldığını gösterse de yaşanan kaotik ortam nedeniyle kayıt altına alınamayan birçok ölüm ya da kaçış da yaşanmıştır. Ülke dışına kaçmak zorunda olan Suriyelilerin bir çoğu ilk etapta uluslararası hukuktan doğan haktan da faydalanarak sınır komşularına sı̆̆ınarak öncelikle can güvenliklerini sağlamış olsalar da, ilerleyen dönemde artan ihtiyaçların slğınılan devletler tarafindan kendilerini tatmin edici düzeyde karşılanamamış oluşu, bu insanların yerleştirildikleri kamplardan çıkarak daha iyi bir yaşam arayışlarının da temelini oluşturmuş ve bu anlamda Avrupa Birliği, kendisine sı̆̆ınan mültecilere sağlamayı hukuki düzeyde garanti ettiği olanakları ile en iyi seçeneklerden birisi olarak karşılarına çıkmıştır. Canlarını riske atarak kimi zaman deniz, kimi zaman da kara yoluyla birlik üyesi ülkelere yasal olmayan yollardan giriş yapan mülteciler, göçü kabul etmiş ülke vatandaşlarının psikoloji ve davranışlarını zaman içinde değişstirebilmektedir. Zira ilk etapta duyulan merhamet, insaniyet gibi duygular, mülteci sayısının artması ve bu göçün kalıcı bir hal alma endişesiyle birlikte yerini gergin bir bekleyişe bırakmış durumdadır. Bu çalışmada ise, mülteci krizi sürecinde konuyla ilgili çıkan haberlere, Avrupa Birliği vatandaşlarının tepkileri sosyal medya üzerinden ortaya çıkartılarak, milliyetçilik söyleminin ne denli ön plana çıkartıldı ̆̆ ortaya çıkartılmaya çalışılacaktır. Çalışma kapsamında Youtube video paylaşım sitesi üzerinde Avrupa'nın en çok takip edilen haber paylaşım sitesi olan euronews.com 'un haber portalında 1 Eylül 2015-1 Ekim 2015 tarihleri arasında Suriyeli gö̧̧menlerle ilgili yayınlanan haberlere kullanıcıların yaptığ İngilizce yorumlar içerik çözümlemesi yöntemiyle incelenecektir.
\end{abstract}

Anahtar sözcükler: Suriyeli; mülteci; göçmen krizi; milliyetçilik; sosyal medya

\begin{abstract}
Europe is facing one of the biggest refugee crisis since the World War II. According to the official numbers almost 1 million people from the North African countries have reached to the European Union countries such as Italy, Malta and Spain. When the refugee crisis first appeared, citizens of the countries that accept these people firstly helped these people with mercy and peace. As the time goes on, people started to feel anxiety due to the situation of this crisis. Because as the period of these peoples' duration of stay gets longer, they started to change peoples' psychology. And yet 2011, another big refugee crises appeared in the process of Syrian civil war. Once again according to the official numbers, almost 2 million Syrians left the country and moved to neighbour countries. But as the time goes on, these people started to search for a better life and EU countries were the best choice among others. In this study, based on the news that were appeared in the euronews YouTube channel about the Syrian refugees, the comments of the European citizens are criticised according to content analysis and tried to find out how the nationalism expressions are increased.
\end{abstract}

Keywords: Syrian; refugee; crisis; nationalism; social media

\footnotetext{
${ }^{1}$ Assist. Prof. Dr., University of Adnan Menderes, AYDIN/TURKEY, ozgur.secim@adu.edu.tr 
Seçim, M.Ö. (2015). Reflections of the nationalist expressions to the social media that grows in Europe during the refugee crisis. International Journal of Social Sciences and Education Research, 1 (1), 112-121.

\section{Giriş}

18. yüzyıldan itibaren, Afrikalıların biyolojik anlamda köleliğe elverişli olduğu düşüncesi, Avrupa'lıların bu insanlara farklı gözle bakmalarını ve "öteki" olduklarını iddia etmelerine yol açmış ve o zamana kadarki "öteki" kavramının ana aktörü olan dinin yerini ırk almaya başlamıştır. Ancak yine aynı Avrupa'lılar özellikle yaşadıkları büyük Dünya savaşları sonrasında, milliyetçiliği reddetmeye hatta ondan korkmaya da başlamışlardır. Bu nedendendir ki, uzun bir süredir özellikle Avrupa'nın sosyal bilimler literatürlerinde "milliyetçiliğin son çağı" savı işlenmektedir. Ancak, literatürde iddia edilenin tersinin sosyal hayatta gerçekleşiyor oluşu, beraberinde milliyetçi ya da daha 1rkçı söylemlerin 'siyasal ve toplumsal imgelerin oluşturulmalarında' önemli rol oynamaya devam etmelerini, diğer bir deyişle toplumsal yaşamın en meşru kabul edilen değerlerinden birisi olarak nitelendirilmesini sağlamıştır. Kısacası, nicelik bakımından milliyetçi söylemler azalmamakta bilakis artmaktadır. Dolayısıyla da milliyetçilik olgusunun etnik çatışma ya da uluslararası kriz dönemlerinde ortaya çıkan, fanatik siyasi aktörlerle ilişkilendirilerek tanımlanması, kolaya kaçmak olacaktır (Toumarkine, 2009).

2011 yılından bu yana, Avrupa Birliği üye ülkelerinin kapısını büyük bir mülteci/göçmen krizi çalmaktadır. Suriye'de yaşanan iç savaş sonrası her ne kadar resmi rakamlara göre 130 binden fazla kişinin hayatını kaybettiği, üç milyona yakın kişinin ise ülke dışına çıkmak durumunda kaldığı rapor edilmiş olsa da, yaşanan kaotik ortam nedeniyle kayıt altına alınamayan bir çok ölüm ya da kaçış da yaşanmıştır/halen de yaşanmaktadır. Ülke dışına kaçmak zorunda olan Suriye'lilerin bir çoğu ilk etapta uluslararası hukuktan doğan haktan da faydalanarak sınır komşularına sığınarak öncelikle can güvenliklerini sağlamış olsalar da, ilerleyen dönemde artan ihtiyaçların sığınılan devletler tarafından kendilerini tatmin edici düzeyde karşılananmıyor oluşu, bu insanların yerleştirildikleri kamplardan çıkarak daha iyi bir yaşam arayışlarının da temelini oluşturmuş ve bu anlamda Avrupa Birliği, kendisine sığınan mültecilere sağlamayı hukuki düzeyde garanti ettiği olanakları ile en iyi seçeneklerden birisi olarak karşılarına çıkmıştır. Zira birlik üyesi ülkelerden herhangi birisine yapılacak giriş, beraberinde maksimum 12 aylık sağlık, eğitim ve maddi desteğin de garantisi durumundadır.

Suriye'de yaşanan iç savaş, ülke içindeki farklı güç gruplarının/silahlı örgütlerin sayısının çok oluşu, bununla birlikte konuya "büyük güçlerin"de dahil olarak kendilerine yakın örgütlere silah/maddi yardımda bulunmasıyla içinden çıkılmaz ve sonu gelmez bir hal almıştır. Bu kapsamda hemen hemen her gün yüzlerce Suriye'li ülkelerini terk ederek, ilk etapta komşu ülkelere, ardından da Avrupa Birliği ülkelerine adeta akın etmektedirler. Bu süreçte, konu ile ilgili medyada çıkan haberler, Birlik üyesi içindeki vatandaşların da konu hakkında bilgi sahibi olmasını sağlarken, haberlere verilen tepkiler (yorumlar) vatandaşların konuya merhamet duyguları içinde mi yoksa yabancı düşmanlığı/korkusu içinde mi olduklarına dair bir takım ipuçları da barındırmaktadır. Zira, "Bir merkezden birçok kişiye uzanan geleneksel medyaya karşılık, gerek altyapısı, gerekse de kullanılan yazılımlarıyla simetrik, demokratik, yani egemen olmayan, yurttaşların siyasal karar alma etkinliğine daha geniş yer veren, şeffaf, ağ üzerinden katılımı olanaklı kılan bir iletişim modeli" (Törenli, 2005:159) sunan "yeni medya", Atina demokrasi anlayışındaki gibi tüm yurttaşların siyasal süreçlere aracısız olarak katılabilmelerini de sağlamıştır. Günümüzde nefret söyleminin yayılma biçimleri, Internet ve sosyal ağ olarak da adlandırılan bu yeni medyanın gündelik iletişim dokularında her gün yaratmakta olduğu değişimlerle yakından ilişkilidir. Gazete, radyo, televizyon, hatta cep telefonu gibi diğer temel iletişim teknolojilerinin aksine; yeni medya, etkileşimli kamusal alanlar yaratarak nefret söyleminin yaşam bulabileceği ve yeniden 
Seçim, M.Ö. (2015). Mülteci krizi sürecinde Avrupa'da artan milliyetçilik söyleminin sosyal medyaya yans1mas1. International Journal of Social Sciences and Education Research, 1 (1), 112-121.

üretime girebileceği en elverişli ortamı sağlamıştır (Alankuş, 2005, Erdoğan, Alemdar, 2005). Özellikle sosyal medya diye tabir edilen yeni medyada bu tip söylemler büyük ölçüde ideolojik işlev göstermekte ve toplumsal çatışmaların maddi sebeplerini örterek bizi demokratik çözümlerden uzaklaştırmaktadırlar. Bu örtüyü kaldırmanın tek yolu, o söylemlerin "nefret söylemi" olduğunun üzerine vurgulanarak belirtilmelidir (Poloma, 1993, Macit, 2010, Kongar, 2011, Mardin, 2010, Mutlu, 2005).

\section{Yöntem}

$\mathrm{Bu}$ çalışmada, sözel, yazılı ve diğer materyallerin nesnel ve sistematik bir şekilde incelenmesine olanak sağlayan içerik analizi yöntemi kullanılmıştır. Eldeki yazılı bilgilerin temel içeriklerinin ve içerdikleri mesajların özetlenmesi ve belirtilmesi işlemi olan bu bilimsel yönteme, sosyal bilimler alanında sıklıkla araştırmacılar tarafından başvurulmaktadır (Aziz, 2008, Geray, 2006). Araştırmanın evreni, mülteci krizi sürecinin en çok gündemde olduğu 1 Eylül 2015 ile 1 Ekim 2015 tarihleri arasında, Internet sitelerinin trafiğini takip eden alexa araştırma şirketi tarafindan belirlenmiş olan, Avrupa'nın en çok izlenen haber portalı olan euronews sitesinin, sosyal medya hesabı (Youtube) üzerinden paylaştığı haberlere, yine sosyal medya aracılığı ile gelen izleyiciokuyucu yorumlarıdır. Taranan haberlerin içerikleri İngilizce olduğundan, makale ile ilgili aramada şu anahtar kelimeler kullanılmıştır; "Syrian (Suriyeli)", "refugee (mülteci)" ve "immigrant (göçmen)". Anahtar sözcüklerle yapılan taramalar, YouTube ara yüzünde, kullanıcının yüklediği içeriğin başlık, tanım veya etiket kısmında geçen sözcüklerle eşlenerek arama yapan kullanıcıya sonuç veren bir uygulamadır. Örneklem oluşturulması sürecinde ise 'kartopu örneklem' modeli benimsenmiştir. Kartopu örneklemi, bir bilgi kaynağından edinilen bilgiler ışığında diğer bilgi kaynaklarına gidilerek örneklemin bir kartopu gibi büyüdüğü örneklem seçim yöntemidir. Kartopu örneklem, araştırmacının evrenin büyüklüğü ile ilgili bilgi sahibi olamadığı veya evrene ilişkin bir kayıt bulunmayan durumlarda yararlı bir tekniktir (Kümbetoğlu, 2005:98). Bu çalışmada da, anahtar sözcükler vasıtası ile ulaşılabilen videoların yanı sıra, video haberin izlenmesi sonrasında yine aynı haber portalı içerisinde bulunan 'ilgili videolar' da izlenmiş, böylelikle milliyetçi söylem barındıran farklı içeriklere de (haber konusu aynı olmak kaydıyla) ulaşılabilmiştir. İzlenen videolar içerisinde, çalışmanın amacı ve kapsamının aşılmaması açısından, en çok beğeni (like) almış olan ilk on yorum değerlendirilmeye alınmıştır. Yayınlanan haberlerin milliyetçilik/yabancı düşmanlığı/nefret söylemi gibi unsurlar içerip içermediğine ise, Chon, A. vd. (2012) tarafından geliştirilen, "Sosyal Ağlarda Nefret Söylem Analizi" modeli örnek alınmış ve haberlere verilen yorumlar bu modele göre kategorilendirilmiştir. Chon, A vd. (2012) tarafından geliştirilmiş olan analiz methoduna göre, söylemler bir takım anahtar kelimeler vasıtasıyla kategorilere göre düzenlenmiştir. Bu kategoriler; abartma/yükleme/çarpıtma, küfür/hakaret/aşağılama, düşmanlık/savaş söylemi ve kimlik/mezhep/din nefreti kategorileridir. Bu çalışmada da ortaya çıkartılan sosyal medya yorumları, bu kategorilere göre düzenlenerek incelenmiştir.

\section{Bulgular}

Tarama sonucuna göre, belirlenen anahtar kelimeler ve tarih aralığında, ilgili haber portalın Youtube sosyal medya platformu üzerinden toplamda 20 haberine ulaşılmıştır. Dolayısıyla bu haberlere verilen okuyucu/izleyici yorumları arasında en çok beğeni (like) alan onar, toplamda da 200 adet yorum çalışma dahilinde incelenmiştir. 
Seçim, M.Ö. (2015). Reflections of the nationalist expressions to the social media that grows in Europe during the refugee crisis. International Journal of Social Sciences and Education Research, 1 (1), 112-121.

Tablo 1. Haberlerin yayınlanma tarihlerine göre yayılımı ve okunma oranları: (1 Ekim 2015 itibariyle)

\begin{tabular}{|c|c|c|c|}
\hline $\begin{array}{c}\text { Haberlerin yayınlanma } \\
\text { tarihleri }\end{array}$ & $\begin{array}{c}\text { Haber } \\
\text { Adedi }\end{array}$ & Yüzdesi & $\begin{array}{c}\text { Haberlerin Okunma/İzlenme/T1klanma Rey- } \\
\text { tingi }\end{array}$ \\
\hline 4 Eylül 2015 & 4 & $\% 20$ & 246,322 (toplam) \\
\hline 6 Eylül 2015 & 2 & $\% 10$ & 147,301 (toplam) \\
\hline 10 Eylül 2015 & 2 & $\% 10$ & 145,399 (toplam) \\
\hline 12 Eylül 2015 & 2 & $\% 10$ & 155,435 (toplam) \\
\hline 13 Eylül 2015 & 2 & $\% 10$ & 166,409 (toplam) \\
\hline 14 Eylül 2015 & 2 & $\% 10$ & 177,329 (toplam) \\
\hline 15 Eylül 2015 & 3 & $\% 15$ & 245,767 (toplam) \\
\hline 21 Eylül 2015 & 1 & $\% 5$ & 104,078 \\
\hline 28 Eylül 2015 & 1 & $\% 5$ & 109,111 \\
\hline 29 Eylül 2015 & 1 & $\% 5$ & 118,340 \\
\hline
\end{tabular}

Belirlenen anahtar kelimeler vasıtasıyla ve ilgili videolar aracıllı̆g ile konu ile ilgili toplamda yirmi habere ulaşılmıştır. Haberler Eylül ayının ilk günlerinden itibaren sıklıkla portalda yer bulurken, 10-15 Eylül arasındaki 5 günlük dönemde on bir adet haberle en yoğun dönem yaşanmıştır. Haberlerin okunma/izlenme/tıklanma oranları ise haber başına hesaplandığında sürekli artış göstermiştir ki, bu da izleyicilerin konuya verdikleri önemin gün geçtikçe artış gösterdiğinin en büyük işaretidir.

Tablo 2. Haberlere yapılan toplam yorum sayıları: (1 Ekim 2015 itibariyle)

\begin{tabular}{|c|c|c|c|}
\hline Haber No. & Tarih & $\begin{array}{c}\text { Toplam Yazılan } \\
\text { Yorum Sayısı }\end{array}$ & $\begin{array}{l}\text { Haberlerin Okunma/İzlenme/T1k- } \\
\text { lanma Reytingi } \div \text { Yorum Sayısı }\end{array}$ \\
\hline 1 & 4 Eylül 2015 & 48 & \multirow{4}{*}{1089 kişide 1} \\
\hline 2 & 4 Eylül 2015 & 61 & \\
\hline 3 & 4 Eylül 2015 & 32 & \\
\hline 4 & 4 Eylül 2015 & 85 & \\
\hline 5 & 6 Eylül 2015 & 101 & \multirow[t]{2}{*}{938 kişide 1} \\
\hline 6 & 6 Eylül 2015 & 56 & \\
\hline 7 & 10 Eylül 2015 & 40 & \multirow[t]{2}{*}{1321 kişide 1} \\
\hline 8 & 10 Eylül 2015 & 70 & \\
\hline 9 & 12 Eylül 2015 & 96 & \multirow[t]{2}{*}{863 kişide 1} \\
\hline 10 & 12 Eylül 2015 & 84 & \\
\hline 11 & 13 Eylül 2015 & 77 & \multirow[t]{2}{*}{1270 kişide 1} \\
\hline 12 & 13 Eylül 2015 & 54 & \\
\hline 13 & 14 Eylül 2015 & 99 & \multirow[t]{2}{*}{943 kişide 1} \\
\hline 14 & 14 Eylül 2015 & 89 & \\
\hline 15 & 15 Eylül 2015 & 154 & \multirow{3}{*}{765 kişide 1} \\
\hline 16 & 15 Eylül 2015 & 66 & \\
\hline 17 & 15 Eylül 2015 & 101 & \\
\hline 18 & 21 Eylül 2015 & 88 & 1182 kişide 1 \\
\hline 19 & 28 Eylül 2015 & 185 & 589 kişide 1 \\
\hline 20 & 29 Eylül 2015 & 180 & 657 kişide 1 \\
\hline
\end{tabular}

Belirlenen tarih aralığında incelenen 20 habere yapılan yorum sayıları incelendiğinde ise, yorumlarda sürekli bir artışın olduğunu gözlemlemekteyiz. (Yalnızca 1 gün dışında: 12 Eylül 2015. Suriye'li Ayhan'ın cenazesinin Bodrum kıyılarına vurduğu gün). İncelenen tarih aralığında, ilk dönem haberlere ortalama 40-50 arası yorum gelirken, ay sonunda bu sayının haber başına 175- 
Seçim, M.Ö. (2015). Mülteci krizi sürecinde Avrupa'da artan milliyetçilik söyleminin sosyal medyaya yans1mas1. International Journal of Social Sciences and Education Research, 1 (1), 112-121.

180 arası oluşu, konuya olan ilginin, merakın ve yorum yapma isteğinin ne denli arttığının bir göstergesi olmuştur.

Tablo 3. Haberlere yapılan yorumlarda kullanılan dil: (1 Ekim 2015 itibariyle)

\begin{tabular}{|c|c|c|}
\hline & $\begin{array}{c}\text { Toplam yorumlarda } \\
(\% 100=1766)\end{array}$ & $\begin{array}{c}\text { Taranan yorumlarda } \\
(\% 100=200)\end{array}$ \\
\hline İngilizce yorumlar & $1631(\% 92)$ & $188(\% 94)$ \\
\hline İngilizce dişında dil kullanımı & $135(\% 8)$ & $12(\% 6)$ \\
\hline
\end{tabular}

Yapılan analizde, haberlere yapılan tüm yorumlar ve haberde konu edilen AB ülkeleri incelendiğinde (1766 adet), yorumların \%92'sinin İngilizce, yalnızca \%8'inin İngilizce dışı bir dilde (genellikle yorumcunun ana dilinde) yapıldığı görülmüştür. Bu da bize, yorum yapanların herkesin anlayabileceği ortak bir dil kullanarak duygu ve düşüncelerini ifade etmeye büyük önem verdiklerini göstermektedir.

Tablo 4. Haberlerde konu edilen Avrupa Birliği ülkesi:

\begin{tabular}{|c|c|}
\hline Habere konu olan Avrupa Birliği ülkesi & Haber sayis1 \\
\hline Yunanistan & 5 \\
\hline Macaristan & 3 \\
\hline Avusturya & 3 \\
\hline Almanya & 3 \\
\hline Çek Cumhuriyeti & 2 \\
\hline İsveç & 1 \\
\hline Bulgaristan & 1 \\
\hline Hirvatistan & 1 \\
\hline
\end{tabular}

Chon, A. vd. (2012) tarafından geliştirilen "Social Networks for hate speech (Sosyal medyada nefret söylemi" modeline göre, tarama sonucunda ortaya çıkartılan haberlerin yorumlarında etiket sözcükler sonucunda kategorilere giren yorum sayıları:

Sosyal medyada nefret söylemi modeline göre söylemler bir takım kategorilere ayrılmıştır. Bunlar, abartma/yükleme/çarpıtma; yani bir kişi ya da olaydan yola çıkarak bir topluluğa yönelik olumsuz genellemeler, çarpıtmalar, abartmalar, olumsuz atıflar içeren söylemler (örneğin; " $A v$ rupa ezan sesine boğuldu”), küfür/aşağılama/hakaret; adından da anlaşılabileceği gibi bahsi geçen kişi ya da topluluklarla ilgili, onlar hakkında doğrudan küfür, aşağılama, hakaret içeren sözcükler, kelimeler (örneğin sahtekar, köpek, ve bir takım küfürler gibi), düşmanlık/savaş söylemi; Bir kişi ya da topluluk hakkında düşmanca, savaşı çağnıştıran ifadelerin yer aldığ 1 söylemler. (örneğin nefret ediyorum, tiksiniyorum, savaşmak istiyorum gibi), kimlik/mezhep/din nefreti; doğal bir kimlik öğesinin nefret, aşağılama unsuru olarak kullanıldığı, simgeleştirildiği söylemler. (İslamofobia, Müslüman korkusu, yabancı düşmanlığı, çok kültürlülüğe karşı olmak, 1rkçılık gibi).

Belirlenen tarih aralığ ve etiket kelimelere göre ortaya çıkartılan haberler arasında, her haberin ilk on yorumundan yalnızca 4 haberde tüm nefret söylemi kategorilerine giren yorum bulunmamıştır. Diğer 16 haberin tamamında, tüm kategorilere giren en az bir, toplamda da on yorum ortaya çıkartılmıştır. Ortaya çıkan sonuçlara göre, Suriyeli mültecilerin Avrupa'ya olan göçleri ile ilgili haberlerde sirasıyla;

1. sırada 39 yorum ile $(\% 19,5)$ kimlik nefretine yönelik kelimeler, 2 . sırada 32 yorumla $(\% 16)$ hakaret içeren kelimeler, 3. sırada 28 yorum ile (\%14) din nefretine yönelik kelimeler, 4 . sırada 
Seçim, M.Ö. (2015). Reflections of the nationalist expressions to the social media that grows in Europe during the refugee crisis. International Journal of Social Sciences and Education Research, 1 (1), 112-121.

27 yorumla $(\% 13,5)$ aşağılamaya yönelik kelimeler, 5 . sırada 26 yorumla $(\% 13)$ küfür içeren kelimeler, 6. sırada 12 yorumla (\%6) abartma içeren kelimeler ve yine aynı yüzde ile düşmanlık içeren kelimeler ortaya çıkartılırken bunları, \%3 ile savaş söylemi içeren kelimeler ve \%1 ile yükleme içeren kelimeler takip etmiştir. Haberlere verilen yorumlar arasında mezhep nefreti kategorisinde ise hiç bir yorum ortaya çıkartılmamıştır. Bunun en büyük nedeninin ise, Avrupalıların İslamiyet'in mezheplerinden ziyade genel anlamıyla kendisinden nefret ediyor/korkuyor ya da istemediğinden kaynaklandığı söylenebilir.

\begin{tabular}{|c|c|c|c|c|c|c|c|c|c|c|c|}
\hline & \multicolumn{3}{|c|}{ KATEG0RI 1} & \multicolumn{3}{|c|}{ KATEGORI 2} & \multicolumn{2}{|c|}{ KATEGORI 3} & \multicolumn{3}{|c|}{ KATEGORI 4} \\
\hline & Abarma & Yükleme & Carptma & Kưfür & Hakaret & 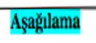 & Düssmanlik & Saras Soyllemi & Kimlik Nefreti & Mehchep Nefreti & Din Nefreti \\
\hline Haber 1 & $\cdot$ & $\cdot$ & . & $1(\% 10)$ & $1(\% 10)$ & $\cdot$ & $\cdot$ & $\cdot$ & $2(\% 20)$ & . & $6(\% 60)$ \\
\hline Haber 2 & & . & $1(\% 10)$ & $2(\% 20)$ & $1(\% 10)$ & $1(\% 10)$ & $2(\% 20)$ & $\cdot$ & $2(\% 20)$ & $\cdot$ & $1(\% 10)$ \\
\hline Haber 3 & $1(\% 10)$ & $\cdot$ & . & $\cdot$ & $1(\% 10)$ & $2(\% 20)$ & . & . & $3(\% 30)$ & $\cdot$ & $3(\% 30)$ \\
\hline Haber 4 & - & . & $\cdot$ & $2(\% 20)$ & $5(\% 50)$ & $2(\% 20)$ & . & $\cdot$ & - & . & $1(\% 10)$ \\
\hline Haber 5 & $\cdot$ & . & $\cdot$ & $3(\% 30)$ & $1(\% 10)$ & $2(\% 20)$ & - & $\cdot$ & $3(\% 30)$ & $\cdot$ & $1(\% 10)$ \\
\hline Haber 6 & $\cdot$ & $\cdot$ & $\cdot$ & $2(\% 20)$ & . & $2(\% 20)$ & $\cdot$ & $\cdot$ & $3(\% 30)$ & $\cdot$ & $3(\% 10)$ \\
\hline Haber 7 & $1(\% 10)$ & $\cdot$ & $\cdot$ & $3(\% 30)$ & $\cdot$ & $2(\% 20)$ & . & $\cdot$ & $3(\% 30)$ & $\cdot$ & $1(\% 10)$ \\
\hline Haber 8 & $3(\% 30)$ & $\cdot$ & $\cdot$ & $2(\% 20)$ & $\cdot$ & $2(\% 20)$ & $\cdot$ & $\cdot$ & $1(\% 10)$ & $\cdot$ & $2(\% 20)$ \\
\hline Haber 9 & $4(\% 40)$ & $\cdot$ & $\cdot$ & $1(\% 10)$ & $\cdot$ & - & . & - & $1(\% 10)$ & . & $4(\% 40)$ \\
\hline Haber 10 & - & . & $\cdot$ & $1(\% 10)$ & $\cdot$ & $3(\% 30)$ & $2(\% 20)$ & $\cdot$ & $2(\% 20)$ & $\cdot$ & $2(\% 20)$ \\
\hline Haber 11 & $\cdot$ & $\cdot$ & $\cdot$ & $1(\% 10)$ & $2(\% 20)$ & $\cdot$ & $\cdot$ & $\cdot$ & $4(\% 40)$ & $\cdot$ & $\cdot$ \\
\hline Haber 12 & - & $\cdot$ & $\cdot$ & $\cdot$ & $\cdot$ & $\cdot$ & $\cdot$ & $4(\% 40)$ & $2(\% 20)$ & $\cdot$ & $\cdot$ \\
\hline Haber 13 & $\cdot$ & $\cdot$ & $\cdot$ & $\cdot$ & $1(\% 10)$ & $3(\% 30)$ & $\cdot$ & $\cdot$ & $1(\% 10)$ & $\cdot$ & $\cdot$ \\
\hline Haber 14 & $\cdot$ & $1(\% 10)$ & $\cdot$ & $\cdot$ & $\cdot$ & $1(\% 10)$ & $3(\% 30)$ & $\cdot$ & $2(\% 20)$ & $\cdot$ & $\cdot$ \\
\hline Haber 15 & $\cdot$ & $\cdot$ & $\cdot$ & $\cdot$ & $3(\% 30)$ & $1(\% 10)$ & $\cdot$ & $2(\% 20)$ & $4(\% 40)$ & $\cdot$ & $\cdot$ \\
\hline Haber 16 & $\cdot$ & $\cdot$ & $1(\% 10)$ & $7(\% 70)$ & $\cdot$ & $1(\% 10)$ & $\cdot$ & $\cdot$ & $1(\% 10)$ & $\cdot$ & $\cdot$ \\
\hline Haber 17 & $\cdot$ & . & $\cdot$ & $\cdot$ & $6(\% 60)$ & $2(\% 20)$ & $\cdot$ & $\cdot$ & $1(\% 10)$ & $\cdot$ & $1(\% 10)$ \\
\hline Haber 18 & $3(\% 30)$ & $\cdot$ & $\cdot$ & $\cdot$ & $4(\% 40)$ & $1(\% 10)$ & $1(\% 10)$ & $\cdot$ & $1(\% 10)$ & $\cdot$ & $\cdot$ \\
\hline Haber 19 & $\cdot$ & $\cdot$ & $\cdot$ & - & $4(\% 40)$ & $1(\% 10)$ & $\cdot$ & - & $2(\% 20)$ & $\cdot$ & $3(\% 30)$ \\
\hline Haber 20 & $\cdot$ & $\cdot$ & $\cdot$ & $1(\% 10)$ & $3(\% 30)$ & $1(\% 10)$ & $4(\% 40)$ & $\cdot$ & $1(\% 10)$ & $\cdot$ & $\cdot$ \\
\hline Toplam & $12(\% 6)$ & $1(\% 0,5)$ & $2(\% 1)$ & $26(\% 13)$ & $32(\% 10)$ & $27(13,5)$ & $12(\% 6)$ & $5(\% 3)$ & $39(\% 19,5)$ & $D(\% 0)$ & $28(\% 14)$ \\
\hline
\end{tabular}


Seçim, M.Ö. (2015). Mülteci krizi sürecinde Avrupa'da artan milliyetçilik söyleminin sosyal medyaya yans1mas1. International Journal of Social Sciences and Education Research, 1 (1), 112-121.

Tablo 5. Tarama sonucuna göre belirlenen haberlerde en çok beğeni alan ilk 10'ar yorumun aldığı beğeni (like) sayıları ve en çok beğeni alan yorumun içerdiği nefret söylemi kategorisi: (1 Ekim 2015 itibariyle)

\begin{tabular}{|c|c|c|c|c|c|c|c|c|c|c|}
\hline HABER & \multicolumn{10}{|c|}{ YORUMLAR/BEĞENI SAYILARI } \\
\hline $\begin{array}{l}\text { Haber } \\
\text { No.1 }\end{array}$ & $\begin{array}{l}\text { Y1: 43 } \\
\text { (kimlik } \\
\text { nefreti) } \\
\end{array}$ & Y2: 40 & Y3: 33 & Y4: 30 & Y5: 22 & Y6: 20 & Y7: 16 & Y8: 11 & Y9: 8 & Y10: 5 \\
\hline $\begin{array}{l}\text { Haber } \\
\text { No. } 2\end{array}$ & $\begin{array}{c}\text { Y1:33 } \\
\text { (din nefreti) }\end{array}$ & Y2: 32 & Y3: 25 & Y4: 22 & Y5: 20 & Y6: 15 & Y7: 11 & Y8: 6 & Y9: 5 & Y10: 3 \\
\hline $\begin{array}{c}\text { Haber } \\
\text { No. } 3\end{array}$ & $\begin{array}{l}\text { Y1: } 46 \\
\text { (küfür) }\end{array}$ & Y2: 17 & Y3: 8 & Y4: 7 & Y5: 5 & Y6: 4 & Y7: 4 & Y8: 2 & Y9: 2 & Y10: 2 \\
\hline $\begin{array}{c}\text { Haber } \\
\text { No.4 }\end{array}$ & $\begin{array}{l}\text { Y1: } 75 \\
\text { (kimlik } \\
\text { nefreti) }\end{array}$ & Y2: 42 & Y3: 29 & Y4: 22 & Y5:20 & Y6: 17 & Y7: 9 & Y8: 4 & Y9: 2 & Y10: 2 \\
\hline $\begin{array}{c}\text { Haber } \\
\text { No. } 5\end{array}$ & $\begin{array}{l}\text { Y1: } 44 \\
\text { (küfür) }\end{array}$ & Y2: 43 & Y3: 28 & Y4: 22 & Y5:21 & Y6: 16 & Y7: 11 & Y8: 9 & Y9: 5 & Y10: 2 \\
\hline $\begin{array}{c}\text { Haber } \\
\text { No.6 }\end{array}$ & $\begin{array}{l}\text { Y1: } 42 \\
\text { (kimlik } \\
\text { nefreti) } \\
\end{array}$ & Y2: 39 & Y3: 20 & Y4: 18 & Y5: 9 & Y6: 6 & Y7: 5 & Y8: 3 & Y9: 2 & Y10: 2 \\
\hline $\begin{array}{c}\text { Haber } \\
\text { No. } 7\end{array}$ & $\begin{array}{c}\text { Y1:26 } \\
\text { (hakaret) }\end{array}$ & Y2: 33 & Y3: 21 & Y4: 19 & Y5:10 & Y6: 9 & Y7: 3 & Y8: 3 & Y9: 2 & Y10: 2 \\
\hline $\begin{array}{c}\text { Haber } \\
\text { No.8 }\end{array}$ & $\begin{array}{c}\text { Y1: } 39 \\
\text { (aşağılama) }\end{array}$ & Y2: 36 & Y3: 22 & Y4: 20 & Y5:17 & Y6: 6 & Y7: 4 & Y8: 4 & Y9: 4 & Y10: 4 \\
\hline $\begin{array}{c}\text { Haber } \\
\text { No.9 }\end{array}$ & $\begin{array}{l}\text { Y1: } 61 \\
\text { (kimlik } \\
\text { nefreti) } \\
\end{array}$ & Y2: 43 & Y3: 22 & Y4: 20 & Y5:11 & Y6: 9 & Y7: 5 & Y8: 4 & Y9: 2 & Y10: 1 \\
\hline $\begin{array}{l}\text { Haber } \\
\text { No. } 10 \\
\end{array}$ & $\begin{array}{l}\text { Y1: } 40 \\
\text { (küfür) }\end{array}$ & Y2: 28 & Y3: 22 & Y4: 20 & Y5:12 & Y6: 8 & Y7: 7 & Y8: 6 & Y9: 3 & Y10: 1 \\
\hline $\begin{array}{l}\text { Haber } \\
\text { No.11 }\end{array}$ & $\begin{array}{l}\text { Y1:33 } \\
\text { (kimlik } \\
\text { nefreti) }\end{array}$ & Y2: 25 & Y3: 22 & Y4: 21 & Y5:20 & Y6: 16 & Y7: 11 & Y8: 10 & Y9: 7 & Y10: 4 \\
\hline $\begin{array}{l}\text { Haber } \\
\text { No.12 } \\
\end{array}$ & $\begin{array}{c}\text { Y1: } 23 \\
\text { (aşağılama) }\end{array}$ & Y2: 22 & Y3:20 & Y4: 11 & Y5: 9 & Y6:5 & Y7: 3 & Y8: 3 & Y9: 3 & Y10: 1 \\
\hline $\begin{array}{l}\text { Haber } \\
\text { No.13 }\end{array}$ & $\begin{array}{c}\text { Y1: } 30 \\
\text { (din nefreti) }\end{array}$ & Y2: 28 & Y3: 22 & Y4: 21 & Y5: 17 & Y6: 11 & Y7: 9 & Y8: 7 & Y9: 3 & Y10: 3 \\
\hline $\begin{array}{l}\text { Haber } \\
\text { No. } 14\end{array}$ & $\begin{array}{l}\text { Y1: } 33 \\
\text { (kimlik } \\
\text { nefreti) }\end{array}$ & Y2: 30 & Y3: 22 & Y4: 22 & Y5: 13 & Y6: 11 & Y7: 10 & Y8: 3 & Y9: 3 & Y10: 1 \\
\hline $\begin{array}{l}\text { Haber } \\
\text { No.15 }\end{array}$ & $\begin{array}{l}\text { Y1: } 42 \\
\text { (kimlik } \\
\text { nefreti) }\end{array}$ & Y2: 33 & Y3: 31 & Y4: 29 & Y5: 28 & Y6: 17 & Y7: 15 & Y8: 14 & Y9: 11 & Y10: 4 \\
\hline $\begin{array}{l}\text { Haber } \\
\text { No.16 }\end{array}$ & $\begin{array}{l}\text { Y1: } 54 \\
\text { (kimlik } \\
\text { nefreti) } \\
\end{array}$ & Y2: 43 & Y3: 22 & Y4: 22 & Y5: 17 & Y6: & Y7: 10 & Y8: 6 & Y9: 4 & Y10: 2 \\
\hline $\begin{array}{l}\text { Haber } \\
\text { No.17 } \\
\end{array}$ & $\begin{array}{c}\text { Y1: 23 } \\
\text { (hakaret) }\end{array}$ & Y2: 18 & Y3: 11 & Y4: 10 & Y5: 5 & Y6: 4 & Y7: 3 & Y8:3 & Y9:3 & Y10:1 \\
\hline $\begin{array}{l}\text { Haber } \\
\text { No.18 } \\
\end{array}$ & $\begin{array}{c}\text { Y1: } 44 \\
\text { (din nefreti) }\end{array}$ & Y2: 40 & Y3: 19 & Y4: 16 & Y5: 15 & Y6: 11 & Y7: 8 & Y8: 7 & Y9: 7 & Y10: 2 \\
\hline $\begin{array}{l}\text { Haber } \\
\text { No.19 }\end{array}$ & $\begin{array}{l}\text { Y1: } 33 \\
\text { (kimlik } \\
\text { nefreti) }\end{array}$ & Y2: 30 & Y3: 22 & Y4: 21 & Y5: 15 & Y6: 13 & Y7: 12 & Y8: 5 & Y9: 2 & Y10: 1 \\
\hline $\begin{array}{l}\text { Haber } \\
\text { No. } 20\end{array}$ & $\begin{array}{l}\text { Y1:31 } \\
\text { (kimlik } \\
\text { nefreti) }\end{array}$ & Y2: 21 & Y3: 13 & Y4: 8 & Y5: 4 & Y6: 2 & Y7: 2 & Y8: 1 & Y9: 1 & Y10: 1 \\
\hline
\end{tabular}

Haberlere yapılan yorumların beğeni sayıları incelendiğinde, en beğenilen yorumların 10 tanesinin kimlik nefreti söylemi barındırdığını ve desteklediğini, 3 tanesinin din nefreti ve küfür barındırdığını, 2'şer tanesinin ise hakaret ve aşağılama barındırdığını görmekteyiz. Dolayısıyla, başka bir kimliğe ya da milliyete yönelik yapılan hakaret, aşağılama ya da nefret söylemleri, incelenen haberler arasında en çok beğeni (like) alan haber yorumları olmuştur. 
Seçim, M.Ö. (2015). Reflections of the nationalist expressions to the social media that grows in Europe during the refugee crisis. International Journal of Social Sciences and Education Research, 1 (1), 112-121.

Tablo 6. Şiddet/nefret/milliyetçi söylem içeren yorumlarda yorumların hedefi: (1 Ekim 2015 itibariyle)

\begin{tabular}{|l|c|c|}
\hline & $\begin{array}{c}\text { Tüm yorumlar içinde } \\
(\% 100=1766)\end{array}$ & $\begin{array}{c}\text { Taranan yorumlar } \\
\text { içinde }(\% 100=200)\end{array}$ \\
\hline Suriyeli mülteciler & $661(\% 38)$ & $46(\% 23)$ \\
\hline Genel olarak mülteciler & $349(19)$ & $22(\% 11)$ \\
\hline Genel olarak Müslümanlar & $301(17)$ & $101(50,5)$ \\
\hline $\begin{array}{l}\text { AB üyesi ülkelerin üst düzey yöneticileri } \\
\text { (Mültecileri kabul edenler) }\end{array}$ & $111(\% 6)$ & $18(\% 9)$ \\
\hline $\begin{array}{l}\text { Suriyelilere destek veren/yardım eden } \\
\text { AB üyesi vatandaşlar }\end{array}$ & $200(\% 11)$ & $3(\% 1,5)$ \\
\hline Türkiye & $144(\% 8)$ & $10(\% 5)$ \\
\hline
\end{tabular}

Çalışma kapsamında incelenen haberlere yapılan yorumlarda, nefret söylemi barındıran yorumların, hedeflerinin kim/kimler olduğuna yönelik yapılan bir söylem analizinde ise, tüm yorumlar içinde Suriye'li mülteciler ilk sırayı alırken, içerik analizine tabi tutulan, en çok beğeni almış olan ilk on yorum incelendiğinde ise bu kez 'genel olarak Müslümanlar'ın en çok hedefte olduğu ortaya çıkmıştır. Diğer bir deyişle yorumlardaki beğeni sayısı, Müslümanlara yönelik (mülteci olsun-olmasın, Suriye'li olsun olmasın) nefret, şiddet ve milliyetçilik söylemi arttıkça daha fazla beğeni almaktadır. Hatırı sayılır bir orada hedefte de, mültecilere evlerini açan, gıda yardımında bulunan ve onları kabul eden $\mathrm{AB}$ üyesi vatandaşlar ile, mültecileri ülke sınırlarına alarak, bir bakıma kendi hayatlarının da içine alan ülke yöneticileri de yer almıştır. Bu durumun siyasal hayatta yansıması olarak da, İsveç'te ve İsviçre'de yapılan son seçimlerde, aşırı sağ partilerin en çok oyu almasını ve Yunanistan gibi ülkelerde de aşırı sağ partilerin oylarını arttırmalarını gösterebiliriz. Yapılan tarama sonucunda ilginç bir sonuç olarak da yorumlardaki hedeflerden birisinin de Türkiye olduğu ortaya çıkmıştır. Türkiye genel olarak mültecilerin Avrupa Birliği topraklarına geçiş güzargahında bir ülke olarak buna müsade etmesinden ve bir sınır komşusu olarak Suriye'lilere yeteri kadar ev sahipliği yapmadığından, kısacası daha fazla Suriye'li barındaması konularında eleştirilmekte. Ancak Suriye'nin diğer sınır komşularının (örneğin Lübnan, Irak) yorumlarda eleştirilmiyor oluşu, Türkiye'nin Avrupa Birliği üye adayı bir ülke olmasından kaynaklandığg şeklinde yorumlanabilir.

\section{Tartışma ve sonuç}

Her ne kadar, Suriye'de patlak veren iç savaşın başlangıç tarihi 2011 olsa da, konuya ilişkin bölge dışında bulunan ülke ve vatandaşlarının bu olaylardan etkilenmesi, 2015 yılında başlayan büyük göç dalgası ile olmuştur. Savaşın ardından ilk etapta hukuki güvencelerden doğan haklarıyla, sayıları yaklaşık 3 milyona ulaşan mülteciler, Irak, Ürdün, Lübnan ve Türkiye gibi sınır ülkelere sığınmıştır. Can güvencelerini sağlayan bu insanlar, ilerleyen dönemde daha iyi bir yaşam umudu ile Avrupa Birliği ülkelerine ama içlerinde kendilerine en çok maddi dersteği sağlayacaklarını düşündükleri Almanya ve İsveç'e doğru, bir ‘umut' yolculuğuna çıkmışlardır. Bu süreçte geçiş yapılan, konaklanan ve hatta yaşamaya başlanılan Avrupa Birliği ülkelerinde ise ne devlet adamları ne de vatandaşlar bu tip büyük bir göç dalgasına hazırlıklı olmamış ve 2. Dünya savaşından bu yana yaşanmayan büyüklükte bir insani krizle karşı karşıya kalmışlardır. Gerek, mülteci sayısının çok yüksek oluşu, gerekse de göç eden mülteciler ile arada olduğuna inanılan hayat standartları farkı ve din farkı, göçü kabul eden insanların psikoloji ve tepkilerini de etkilemiştir. 
Seçim, M.Ö. (2015). Mülteci krizi sürecinde Avrupa'da artan milliyetçilik söyleminin sosyal medyaya yans1mas1. International Journal of Social Sciences and Education Research, 1 (1), 112-121.

Bu çalışmada da Avrupa Birliği üyesi olan Devletlerin vatandaşlarının, konu ile ilgili çıkan haberlere, karşılıklı etkileşimin sağlandığı bir ortam olduğundan, kendisinin de bir sosyal medya aracı olarak kabul edilen Youtube üzerinde verdikleri tepkiler ve bu tepkilerdeki nefret/şiddet ve milliyetçi söylemleri incelenmiştir. Çalışma, Avrupa'ya geçiş yapan/yapmaya çalışan mülteci sayısının en yüksek olduğu 1 Eylül ile 1 Ekim 2015 tarihleri arasında gerçekleştirilmiştir. Bu dönem aralığında incelenen sitede toplam 20 adet habere ulaşılmış ve çalışmanın amaç ve içeriğini aşmaması bakımından bu haberlere gelen yorumların en çok beğeni almış ilk on yorumu değerlendirilmiştir. Haberlere yapılan yorum sayıları incelendiğinde, haber sayısının arttığı gibi, yapılan yorum sayısının da arttığını gözlemlemekteyiz.

Her ne kadar Suriye'deki iç savaş, ya da sınır komşularına sığınan Suriyeliler ile ilgili haberlere Avrupa vatandaşları pek ilgi göstermiyor ve yorum yazmıyor olsa da konu kendi ülkelerine giriş yapan yabancılar olduğunda konuya olan ilgileri de bir hayli artmıştır. 3 yaşındaki Ayhan'ın cenazesinin Bodrum kıyılarına vurduğu gün dışında konu ile ilgili yayınlanan her haberde yorum sayısı artmıştır, yorumlara bağlı olarak milliyetçilik ve nefret söylemleri de o oranda artmıştır. Yine aynı şekilde, haberlerde konu edilen ülkeler arasında resmi dili İngilizce olan hiçbir Avrupa Birliği ülkesi yokken, yapılan yorumların \%92'sinin (1631 yorum) İngilizce, yalnızca \%8'inin (188 yorum) yorumcuların ana dilinde yapılmış oluşu, konu ile ilgili yapılan tartışmalarda bir ortak dil arayışının, birbirini daha iyi anlama çabasının ve kullanılan nefret/ayrımcı/milliyetçi söylemlerin daha büyük kitlelere yayılması çabasını bizlere göstermektedir. Kategorilendirilen nefret söylemi çeşitlerinden ise, en çok ortaya çıkartılanlar sırasıyla, kimlik nefreti, hakaret, din nefreti, aşağılama ve küfür olarak ortaya çıkmıştır. Diğer bir deyişle, Suriyeli mültecilerle ilgili yapılan yorumlarda, kendilerinin kimlikleri ve mensubu oldukları dinle ilgili aşağılama, hakaret ve küfür içeren yorum sayısı incelenen toplam yorum sayısının yarısı kadardır.

Dahası, bütün bu küfür, hakaret ve aşağılama içeren yorumların tamamına yakınının, yorumu yapanın veya yorumla alakası olan ülkenin diliyle değil, İngilizce yapılıyor oluşu, sosyal medyanın daha çok insana erişme gücüyle birlikte bir Dünya dili olan İngilizcenin bunca nefret söylemine aracılık ettiriliyor oluşunun göstergesidir. Çalışmada en çok beğeni alan yorumlara yönelik yapılan bir detaylı incelemede ise en çok beğeni alan yorumların hepsinde kategoriye dahil olan bir yorumun bulunduğunu, bu yorumlar arasında ise en çok yine kimlik nefreti ile ilgili yorumların beğenildiğini görmekteyiz. Diğer bir deyişle, yorumda nefret söylemi arttıkça beğeni sayısı da artmaktadır. Son olarak ise, incelenen tüm yorumlarda, yorumun hedefinin \%38 ile Suriyeli mülteciler olurken, en çok beğeni alan ilk on yorumda \%50,5 ile hedefin genel olarak Müslümanlar oluşu, olayın mülteci sorununa yönelik bir öfkeden ziyade, topyekûn dine yönelik bir nefret, tahammülsüzlük olduğu ortaya çıkmaktadır.

\section{Kaynakça}

Alankuş, S. (Ed.) (2005). Yeni İletişim Teknolojileri ve Medya İstanbul: IPS İletişim Vakfı Yayınları.

Aziz, A. (2008). Sosyal Bilimlerde Araştırma Yöntemleri ve Teknikleri Ankara: Nobel Yayın Dă̆ııım.

Chon, A. vd. (2012). Social Networks for Hate Speech, http://goo.gl/wzaoCp Erişim Tarihi: 27.10.2015.

Erdoğan, İ., Alemdar, K. (2005). Öteki Kuram Ankara:Erk.

Geray, H. (2006). Toplumsal Araştırmalarda Nicel ve Nitel Yöntemlere Giriş Ankara: Siyasal Kitapevi

Kongar, E. (2011). Toplumsal Değiş̧me Kuramlarl ve Türkiye Gerçeği İstanbul: Remzi Kitapevi.

Krug, S. (2007). Kullanışlı Web Siteleri Yaratma Gönül Taban Çolak (Çev). İstanbul: Açık Akademi. 
Seçim, M.Ö. (2015). Reflections of the nationalist expressions to the social media that grows in Europe during the refugee crisis. International Journal of Social Sciences and Education Research, 1 (1), 112-121.

Kümbetoğlu, B. (2005). Sosyolojide ve Antropolojide Niteliksel Yöntem ve Araştırma İstanbul: Bağlam Yayınc1lik.

Macit, M. (2010). Türkiye'de Toplumsal Değişim ve Siyaset: Siyasal Afiş ve İlanların Dilinden İstanbul: Birey Yayınc1lik.

Mardin, Ş. (2010). Siyasal ve Sosyal Bilimler İstanbul: İletişim.

Mutlu, E. (2005). Kitle İletişim Kuramları Ankara: Ütopya Yayınevi.

Toumarkine, A. (2009). İthal Milliyetçilik ile Etki Altındaki Milliyetçilik Arasında. Tanıl Bora ve Murat Gültekingil (Ed.), Modern Türkiye'de Siyasi Düşünce: Milliyetçilik içinde (s. 934-939). İstanbul: İletişim Yayıncılık.

Törenli, N. (2005). Bilişim Teknolojileri Temelinde Haber Medyasının Yeniden Biçimlenişi: Yeni Medya, Yeni Illetişim Ortamı. Ankara: Bilim ve Sanat Yayınları

Poloma, M.M. (1993). Çăgdaş Sosyoloji Kuramları Hayriye Erbaş (Çev). Ankara: Gündoğan Yayınları. 
Seçim, M.Ö. (2015). Mülteci krizi sürecinde Avrupa'da artan milliyetçilik söyleminin sosyal medyaya yans1mas1. International Journal of Social Sciences and Education Research, 1 (1), 112-121.

\section{Extended Abstract in English}

Nobody can predict where will be the next war or who will be defined as 'refugee' or 'migrant'. Since the World War one and World War two, Syrian interior war has become the biggest one so far. And due to this war, almost 4 million people has abandoned their homes and lives. (Officially nobody can predict how many people escaped from Syria, due to the chaos ambiance.) So far, Syrian's next-door countries such as Turkey, Iraq and Lebanon, accepted almost 2 millions of these people but as the time goes on these people keep coming. And the ones live in the next-door countries have started to search for a better life for themselves after guaranteeing their living. Such as better education, better health, better income etc. And the next stop or step of these people is the European Union countries, thanks to their economic welfare.

Once these people have started to reach the European Union countries, people living in these countries started to feel anxiety due to the diversities of these people such as the 'living standards', 'health' and 'religion' and so on. The more of the duration of these peoples' stay get longer, the more European Union countries peoples' anxiety get higher. And this worry started to reflect to the daily life of these people such as their social network life. In this study, I tried to find out what these people (European Union country citizens) think and reflect to the social media about these Syrian refugees or generally the Syrian interior war and its impacts on their own lives. In order to do that, I examined the social media platform of the news web page of euronews.com, which is the most, read and liked one among the others in Europe according to www.alexa.com (the statistical web page which tells which web page is visited most/or least). And the news which were published about the Syrian refugee problems are researched among others by using the keys words of 'Syrian', 'refugee' and 'immigrant'. And after that, the news which were found out are examined by the model of "Social Networks for hate speech" which was made by Chon and others. (2012).

To this examination, the speeches are categorized by some key words such as, "hate of religion speech words", "hate of nationality speech words", "hate of sectarian speech words", "speech of insult words", "speech of contempt words", " exaggeration speech words". And the results were as not the ones that the European Union citizens were claiming. European Union citizens were claiming that the idea of nationalism has passed away from their countries long time ago. But the results do not say so. The results say that, the more of hate speech, nationalist speech and foreign hate speeches increase, the more 'likes' to these speeches are increases.

While I examine the target of these speeches, it is found out that the European Union countries' peoples' main target is not the refugees but their religion; which is Islam. The examination of the language of the comments showed us that almost all the people in Europe do speak English while they are commenting on social media rather than their native languages. And this result also showed us that, people try to find a general language to express their feelings plus to try to persuade people about how they think. For example, s user from Spain, do not speak with his/her native language, and he/she refers to speak English, in order to reach more and more people to persuade. The comments' targets are also an interesting outcome of the article also. According to the results of the question of, "what is the target of the bad comments?" has been found that mostly it is related with the refugees, but when the most liked comments are focused it is found out that the comments related with the hate of Islam are the most liked ones. This means that, people like the comments of hate of Islam more than the ones related with the refugee problem. 
Seçim, M.Ö. (2015). Reflections of the nationalist expressions to the social media that grows in Europe during the refugee crisis. International Journal of Social Sciences and Education Research, 1 (1), 112-121.

Another interesting outcome of this question is one of the target group is the people who helps the refugees that enter to the European Union; which means that many people in European Union, do not like the people who helps the foreign ones, or the ones who are not Christian. And last target was the country of Turkey; which is criticized mostly for not hosting enough Syrians (whereas only in the city of Istanbul there are 1,5 million of them) and also letting some Syrians to enter to the European Union borders. 